\title{
Determinants of Foster Care Placement For the Maltreated Child
}

\author{
Desmond K. Runyan, MD, MPH, Carolyn L. Gould, MD, \\ Donald C. Trost, MD, MS, and Frank A. Loda, MD
}

\begin{abstract}
This study examined the records of the North Carolina Central Registry of Child Abuse and Neglect to determine which social, family, and child characteristics were most influential in the decision to place a child in foster care. These records contained all theoretically relevant factors as well as demographic data. Analysis included the computation of odds ratios for foster care for each of 250 variables. A maximum likelihood logistic regression model was constructed to obtain the independent and cumulative contribution of each factor. Some expected variables such as parental stress factors (substance abuse) and types of abuse
\end{abstract}

(burns and scalds) placed a child at a significant risk for placement in foster care $(p<0.01)$. However, less obvious factors such as referral source (law enforcement agencies) or geographic area also placed children at risk. Overall, the model explained little of the variance of these decisions $\left(R^{2}=0.168\right)$ and poorly predicted placement (sensitivity 66.3 per cent, specificity 74.6 per cent). Using existing data, we were unable to adequately describe the decision process in selecting foster care. (Am J Public Health 1981;71:706-711.)
Because of the serious sequelae, ${ }^{1-3}$ those who report suspected child abuse or neglect are concerned that appropriate and effective intervention follow the report. Responsibility for the actual direction of services for confirmed reports lies with the local child protective agency. This division of labor between health and social agencies is relatively unique to the area of child maltreatment and prompted us to explore which factors are actually related to the selection of treatment.

Experts in the area of child maltreatment agree on a general approach to the dysfunctional family. ${ }^{4-7}$ This should include a multi-disciplinary, multi-service plan for each family. Services may include counseling, lay therapists, day care services, and homemaker aides. Removal of the child from the home, or "rescue," is advocated only when the child appears to be in danger of further maltreatment. This would be indicated by evidence of repeated abuse, a child who is unable to protect himself/herself, or parents who are unable or unwilling to cooperate with the involved agencies.

Despite this expert agreement, there are many factors which may alter the approach taken by "front line" social workers. First, the variability of resources among communi-

Address reprint requests to Dr. D.K. Runyan, c/o The Robert Wood Johnson Clinical Scholars Program, University of North Carolina School of Medicine, Chapel Hill, NC 27514. Both Drs. and Gould were Clinical Scholars and affiliated with the pediatric department. Dr. Runyan is now assistant professor of social medicine and pediatrics at UNC. Dr. Gould is assistant professor of pediatrics at the University of Maryland. Dr. Trost, a doctoral candidate in biostatistics at UNCSPH, is currently with the Department of Pathology at the University of Florida. Dr. Loda is professor of pediatrics and lecturer in maternal and child health at UNC. This paper, submitted November 13, 1980, was revised and accepted March 9, 1981.

Editor's Note: See also related editorial, p. 685, this issue. ties may make one or more services unavailable to families. Second, the high "burn-out" rate of protective services workers ensures that many workers will be inexperienced. ${ }^{8}$ Workers, therefore, may not be familiar with standard recommendations nor capable of determining which families will benefit most from a given service. Finally, the treatment decision is not solely the responsibility of the social worker: court action may supersede a worker's recommendations.

This study was designed to determine which factors were most influential in deciding to place a child in foster care. This decision involves the greatest change for the family and the most difficult decision for the social worker.

\section{Methods}

The State of North Carolina maintains a Central Registry to collect data from all reports of child maltreatment made to individual county departments of social service within the state. ${ }^{9}$ The individual reports are forwarded to the registry on a checklist reporting form similar to the American Humane Association's standard form 0024. ${ }^{*}$ Each report includes information about the county of residence, source of original referral, presence of familial stress factors, parental characteristics (role in the incident, age, race, income, education, occupation, marital status), child characteristics (age, race, sex, type of maltreatment, severity, number of siblings also involved, presence of handicaps), and the disposition or types of services provided in each case.

The central registry provided records from all confirmed

${ }^{*}$ Available from American Humane Association, P.O. Box 1266, Denver, CO 80201. 
reports of maltreatment received between July 1978 and June 1979. The names were deleted to preserve confidentiality. Those records which reported first episodes of maltreatment by a member of the family were selected for analysis. In cases where more than one child in the family was reported, the first listed child was selected for study so that the characteristics of multi-child families would not be overrepresented. Examination of these reports revealed that 97 per cent of the information needed was available and that the records were internally consistent with seemingly appropriate distributions between legal and social dispositions, and the type and severity of maltreatment.

We carefully examined the decision to use only the first listed child in each report since nearly 40 per cent of the reports listed more than one victim child. There was no correlation between the rank order of the child in multiple listed reports and age, sex, or type and severity of maltreatment. The role that the presence of more than one child might play in influencing the decision was included in our analyses.

The checklist form of report allowed a maximum of 37 characteristics or values to be reported from among 150 possibilities. Two categories-type of maltreatment and familial stress factors-permitted up to five responses; all other categories required a single response. Appendix I lists the familial stress factors included in our data base. With the exception of the age of child and age of each parent, the $\mathbf{1 5 0}$ possible characteristics or values were converted to binary or "dummy" variables. The 100 counties were also converted to 100 binary variables although only one county variable could be positive for each report.

Crude odds ratios were calculated to estimate the relative odds of a child's removal after maltreatment in the presence of each individual characteristic or value compared with the absence of that characteristic ${ }^{10} .11$ The counties of residence were also used as separate independent or exposure variables. Counties of residence were grouped by per capita income, urban/rural composition, financial aid provided by the social service agency, type of industry, and district court, in order to obtain additional exposure variables. A maximum likelihood logistic model was constructed in order to calculate the relative and cumulative association of each variable with removal from the home with control for confounding. ${ }^{12}$ Initial stepwise regression analyses were performed for each category of variables such as referral source, type of abuse, etc. Additional stepwise regressions were run for the theoretically possible interactions. All the binary variables and interaction terms that were significant at the $p<0.10$ level were put into a final model along with several variables that had been expelled from the earlier regressions but which we still considered important. The final model was achieved through a backwards elimination procedure. Our program calculated a logistic regression coefficient for each term as well as a correlation coefficient and a $P$ value. An analog of the squared multiple correlation coefficient, $R^{2}$, was calculated to estimate the relationship between the model and actual practice.

Adjusted odds ratios were then calculated for each significant variable using the regression coefficients from the model. ${ }^{13}$ These ratios express the relative odds for removal when all the other significant characteristics are controlled (see Appendix II).

Finally, we used the logistic regression model to predict placement in foster care and compared this to the actual placement by social services. From this comparison we obtained the model's sensitivity, specificity, and predictive value.

\section{Results}

During the study period, 8,610 children were reported to the Central Registry for confirmed maltreatment. Of these, 7,770 were first reports. Forty per cent of the families had more than one child reported. Nearly 15 per cent, 685 families, had a child placed in foster care.

Sixty-seven per cent of the families were White, 29 per cent were Black. Seventy-one per cent of the parents were either unemployed or employed in unskilled labor positions. Only 17 per cent of the parents were high school graduates. The mean parental age was 31.95 years. The mean age of the children was 7.36 years. There were equal numbers of males and females involved although females predominated in the teenage years. The most common types of maltreatment were cuts and bruises, physical neglect, and lack of supervision. Sixty-six per cent of the children required no medical treatment. These characteristics of the parents and children are similar to those found in national registries. ${ }^{14}$

As shown in Table 1, some of the child and family characteristics related to expert guidelines for foster care did put children at increased risk for placement. These characteristics included parents who perceived severe punishment as acceptable, parents with substance abuse problems, severe injuries requiring hospitalization, abandonment of young children, and more severe types of abuse. Factors which were not significant included the age of child or parent, the presence of several maltreated children in one family, and several specific types of abuse (e.g. sexual abuse, skull or bone fractures).

Many factors which would not logically play a role in the decision to place a child in foster care were found to put a child at higher risk for placement. These included specific referral sources and geographic divisions. Cases referred by the courts and police were at two to four times higher risk for removal, even after adjusting for the types of maltreatment and severity. Individual counties placed from 0 to 48 per cent of the children reported. This variation appeared to be linked to court jurisdiction. Six court districts differed significantly from the state average with adjusted odds ratios ranging from 0.43 to 4.31 .

There was little evidence of actual bias in these decisions. Race, income, and education were non-significant. Occupation was also non-significant, with the exception of military fathers. However, children from military families had an adjusted odds ratio of 1.79 for placement in foster care.

Despite the above significant risk factors, the final logistic model (Table 2) did not strongly associate these multiple characteristics with the removal of children from 
TABLE 1-Estimated Risk of Foster Care in the Presence of Specific Characteristics

\begin{tabular}{|c|c|c|}
\hline Characteristic & $\begin{array}{l}\text { Crude Odds Ratio } \\
\qquad(95 \% \mathrm{Cl})^{\star}\end{array}$ & $\begin{array}{c}\text { Adjusted Odds Ratio } \\
(99 \% \mathrm{Cl}) \dagger\end{array}$ \\
\hline \multicolumn{3}{|l|}{ County of Residence } \\
\hline $\begin{array}{l}\text { County } L \\
\text { County } M\end{array}$ & $\begin{array}{l}5.53(3.28,9.32) \\
3.37(2.15,6.49)\end{array}$ & $\begin{array}{l}4.31(1.38,13.47) \\
3.47(1.17,10.33)\end{array}$ \\
\hline \multicolumn{3}{|l|}{ Residence in Counties } \\
\hline \multicolumn{3}{|l|}{$\begin{array}{l}\text { Grouped by District } \\
\text { Court Jurisdiction }\end{array}$} \\
\hline District Court A & NS & $2.06(1.30,3.27)$ \\
\hline District Court B & NS & $1.65(1.33,2.04)$ \\
\hline District Court C & $0.35(0.22,0.55)$ & $0.53(0.35,0.79)$ \\
\hline District Court D & $0.34(0.19,0.60)$ & $0.43(0.22,0.85)$ \\
\hline District Court Eł & $1.48(1.10,2.00)$ & \\
\hline For 1-year-old child & & $1.13(1.03,1.25)$ \\
\hline For 15-year-old child & & $2.09(1.01,4.38)$ \\
\hline \multicolumn{3}{|l|}{ Source of Original Report } \\
\hline Court & $2.81(1.70,4.65)$ & $4.02(1.46,11.08)$ \\
\hline Victim & $2.75(1.74,4.33)$ & $2.85(1.37,5.95)$ \\
\hline Police & $2.14(1.70,2.27)$ & $2.62(1.87,3.69)$ \\
\hline Minister & $4.12(1.30,13.0)$ & NS \\
\hline Hospital Physician & $1.74(1.14,2.70)$ & NS \\
\hline School Personnel & $0.36(0.26,0.60)$ & NS \\
\hline \multicolumn{3}{|l|}{ Family Characteristics } \\
\hline Perpetrator Abused as Child & $2.20(1.42,2.87)$ & $1.82(1.33,2.50)$ \\
\hline Severe Discipline Acceptable to Perpetrator & NS & $1.70(1.38,2.09)$ \\
\hline Alcohol or Drug Abuse & $1.97(1.64,2.38)$ & $1.57(1.31,1.90)$ \\
\hline Lack of Family Social Support & $1.46(1.17,1.81)$ & $1.35(1.22,1.48)$ \\
\hline Mental Health Programs & $2.01(1.66,2.43)$ & NS \\
\hline Marital Discord & $1.40(1.14,1.70)$ & NS \\
\hline Inadequate Income & $1.23(1.04,1.46)$ & NS \\
\hline \multicolumn{3}{|l|}{ Parent Characteristics } \\
\hline Widowed Father & $2.30(1.28,4.13)$ & $2.56(1.13,5.81)$ \\
\hline Military Occupation & $13.56(8.56,21.5)$ & $1.79(1.22,2.64)$ \\
\hline \multicolumn{3}{|l|}{ Type and Severity of Abuse } \\
\hline Hospitalization Required & $2.37(1.76,3.21)$ & $1.79(1.33,2.41)$ \\
\hline Negligible Injuries & $0.58(0.49,0.69)$ & $0.59(0.50,0.69)$ \\
\hline Abandonment‡ & $5.20(3.97,6.82)$ & \\
\hline 1-year-old child & & $10.19(2.26,45.9)$ \\
\hline 15-year-old child & & $3.48(1.08,13.6)$ \\
\hline Parental Drug Abuse and Abandonment & & $3.08(1.63,5.80)$ \\
\hline Burns, Scalds & $2.77(1.60,4.82)$ & $2.37(1.14,4.96)$ \\
\hline Physical Neglectł & $1.45(1.22,1.72)$ & \\
\hline 1-year-old child & & $2.17(1.52,3.11)$ \\
\hline 15-year-old child & & $1.12(1.02,1.23)$ \\
\hline Emotional Neglect & $1.83(1.53,2.19)$ & $2.09(1.65,2.65)$ \\
\hline Malnutrition & $2.23(1.37,3.65)$ & $2.01(1.19,3.40)$ \\
\hline Both Abuse and Neglect & $2.06(1.63,2.60)$ & $1.56(1.33,1.83)$ \\
\hline Lack of Supervision & NS & $1.17(1.12,1.23)$ \\
\hline Skull Fracture & $5.32(2.34,12.1)$ & NS \\
\hline Bone Fractures (except skull) & $3.54(1.81,6.92)$ & NS \\
\hline Sexual Abuse & $1.95(1.42,2.60)$ & NS \\
\hline
\end{tabular}

"Confidence intervals calculated for raw data with EPISAS Package. ${ }^{10}$

†Confidence intervals calculated from mathematical model; $99 \% \mathrm{Cl}$ used because of multiple comparisons. $\ddagger$ Includes interaction for calculation of adjusted odds ratios.

NS Not significant.

"Other factors with no significant relationship to foster care placement included: parental age; race; marital status; education; occupation (exclusive of the military); estimated income and supplemental income; age of child; presence of handicap in child prior to maltreatment; number of children reported as maltreated in same family.

the home. The total $R^{2}$ (variation explained) was only $0.168{ }^{* *}$ This would indicate that 83.2 per cent of the variation was due to factors not included in this data base. This fact is emphasized by the model falsely predicting

**The reader is referred to the discussion by Gordon et al on the meaning of $R^{2}$ in this type of analysis. ${ }^{15}$ removal 68.7 per cent of the time and having a false negative rate of 7.3 per cent (Table 3 ).

\section{Discussion}

Our results emphasize the great difficulties facing protective service agencies. The correlation with some factors 
TABLE 2-Logistic Regression Model for Foster Care Placement

\begin{tabular}{|c|c|c|}
\hline Variable & $\begin{array}{l}\text { Correlation } \\
\text { Coefficient }\end{array}$ & Beta \\
\hline \multicolumn{3}{|l|}{ Abuse Factors } \\
\hline Abandonment & $0.155^{\star}$ & 2.39 \\
\hline Emotional Neglet & $0.133^{*}$ & 0.73 \\
\hline Physical Neglet & $0.076^{*}$ & 0.82 \\
\hline Negligible Injuries & $-0.074^{\star}$ & -0.53 \\
\hline Abuse and Neglect Present & $0.052 \ddagger$ & 0.44 \\
\hline Hospitalization Required & $0.047 \ddagger$ & 0.58 \\
\hline Skull Fracture & $0.045 \ddagger$ & 1.35 \\
\hline Burns and Scalds & $0.042 \ddagger$ & 0.86 \\
\hline Malnutrition & $0.039 \S$ & 0.70 \\
\hline Lack of Previous Handicap & $-0.042 \ddagger$ & -0.27 \\
\hline Lack of Supervision & $0.021 \ddagger$ & 0.12 \\
\hline \multicolumn{3}{|l|}{ Parent Factors } \\
\hline Parent Accepts Severe Discipline & $0.056 t$ & 0.53 \\
\hline Unemployed Mother & $0.050 \ddagger$ & 0.31 \\
\hline Parent Abused as Child & $0.047 \ddagger$ & 0.60 \\
\hline Widowed Father & $0.045 \ddagger$ & 0.94 \\
\hline Unmarried Mother & $0.039 \S$ & 0.33 \\
\hline Substance Abuse & $0.046 \mp$ & 0.46 \\
\hline Military Father & $0.036 \S$ & 0.58 \\
\hline Lack of Social Support & $0.038 \S$ & 0.30 \\
\hline \multicolumn{3}{|l|}{ Geographic Factors } \\
\hline County L & $0.077^{*}$ & 1.46 \\
\hline County M & $0.059 \dagger$ & 1.25 \\
\hline District Court A & $0.048 \ddagger$ & 0.72 \\
\hline District Court B & $0.047 \ddagger$ & 0.50 \\
\hline District Court D & $-0.043 \ddagger$ & -0.84 \\
\hline District Court C & $-0.042 \ddagger$ & -0.63 \\
\hline \multicolumn{3}{|l|}{ Referral Source } \\
\hline Court & $0.079^{*}$ & 1.39 \\
\hline Victim & $0.062 \dagger$ & 1.04 \\
\hline Ministers & $0.044 \ddagger$ & 1.86 \\
\hline Police & $0.113^{*}$ & 0.97 \\
\hline \multicolumn{3}{|l|}{ Interaction Terms } \\
\hline Abandonment/Substance Abuse & $0.048 \dagger$ & 0.67 \\
\hline Age/District Court E & $0.044 \ddagger$ & 0.14 \\
\hline Emotional Neglect/Substance Abuse & $-0.039 \S$ & -0.55 \\
\hline Age/Physical Neglect & $-0.038 \S$ & -0.05 \\
\hline Age/Abandonment & $-0.036^{\star}$ & 0.07 \\
\hline Age/Sexual Abuse & $0.034^{\star}$ & 0.09 \\
\hline & Total $R^{2}=0.168$ & \\
\hline
\end{tabular}

*p $<0.0001$

tp $<0.001$

$\neq \mathrm{p}<0.01$

\$p $<0.05$ which should enter the decision to remove a child suggests that protective service workers are cognizant of current recommendations. However, the wide geographic differences point out the limitations of this system. The reasons for these geographic differences are probably multiple.

The first of these is almost certainly the influence of the judicial system. In North Carolina one or all of the judges in a district may hear child protection cases. Obviously, they differ in both their training and anecdotal experience. Also, the relationship between protective service agencies and the judiciary varies widely from county to county and time to time. It is therefore almost unreasonable to expect consistent treatment across district lines.

The autonomous county department system may explain a substantial part of the difference. Counties with large budgets will be able to offer families more services and also may have more foster homes available. Another factor resulting in county differences would be the treatment preferences of agency supervisors and their influence within the system.

Finally, because of the wide variety of cultures and social structures present in this state, there may be actual differences in both types of maltreatment and the necessity for foster care. Our attempts to elucidate such a relationship by grouping counties by urban/rural composition, types of industry, etc., were unsuccessful. It would appear that such cultural and social variables were not represented in our data base and could not be evaluated.

The relationship between the source of the referral and the treatment decision has been noted by another investigator. ${ }^{16}$ One might assume that the law enforcement agencies would receive reports of more serious maltreatment and that this accounts for the higher rate of removal. However, our data, when adjusted for severity and type of abuse (adjusted odds ratios) still confirmed higher risks of removal for children reported to these agencies. This may imply that law enforcement agencies and the courts have a greater input into the removal decision and tend to "rescue" a child more frequently.

The variations in practice that we observed are unlikely to be the result of inaccurate or misleading reports sent to the central registry. The forms are relatively simple to complete and a state manual is used to guide responses. Since the reports are filled out after initial decisions have been made, one might expect recall bias of the salient

TABLE 3-Comparison of Actual Foster Care Placement with Prediction from Mathematical Model

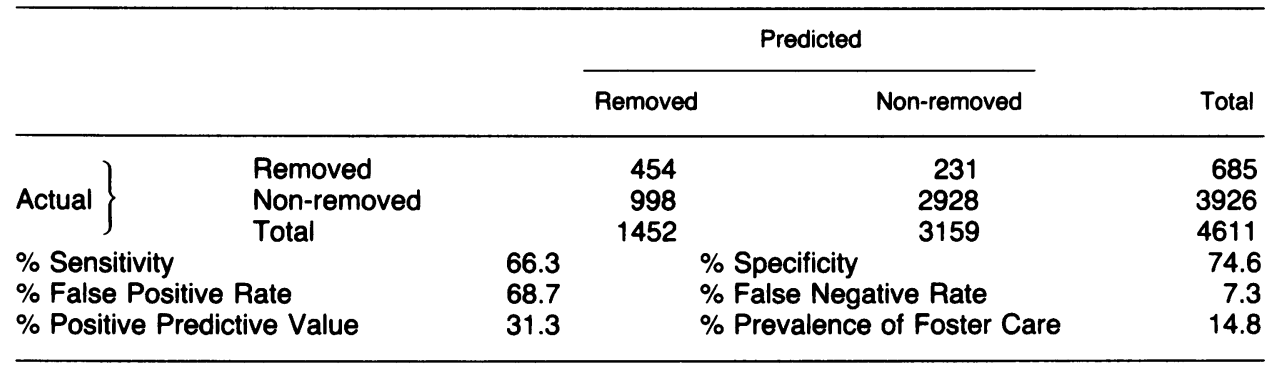


characteristics of each case to influence the data. A bias of this sort would be expected to result in the discovery of more uniform differences between the children in foster care and those left in their homes. A more serious problem is the bias that might have resulted from underreporting of cases to the central registry. State officials estimate that only 50 per cent to 70 per cent of all reports of child abuse or neglect reach the central registry. Underreporting is thought to occur less frequently among confirmed reports; our use of confirmed reports should have minimized this bias.

Our model had a low $\mathrm{R}^{2}$ value and poorly predicted removal from the home. We interpret this to mean that assignment to foster care approximates a random process across a large population. It is unlikely that individual cases are ever decided randomly; rather, the multitude of reasons used tend to cancel each other out when applied to large numbers. Similar effects have been observed in several medical situations, including the decision for coronary bypass surgery ${ }^{17}$ and should not be viewed as a condemnation of the social professions. Instead, it reflects the uncertainty of the effectiveness of a given treatment. Further studies of the effectiveness of treatment are necessary to help resolve this problem.

\section{REFERENCES}

1. Kempe CH, Silverman FN, Steele BF, et al. The battered child syndrome. JAMA 1962; 181:17-24

2. Elmer E: Developmental characteristics of abused children. Pediatrics 1967; 40:596-602.

3. Glazer HH, Heagarty MC, Bullard DM, Pivchide EC: Physical and psychological development of children with early failure to thrive. J Pediatr 1968; 73:690-697.

4. Martin HP: Treatment for Abused and Neglected Children. Washington, DC: National Center on Child Abuse and Neglect, DHEW Pub. No. (OHDS) 79-30199, 1979.

5. Jenkins J, Salus M, Schultze G: Child Protective Services: A Guide for Workers. Washington, DC: National Center on Child Abuse and Neglect, DHEW Pub. No. (OHDS)79-30203, 1979.

6. Schmitt B: The Child Protection Team Handbook. New York: Garland Press, 1978.

7. Helfer R, Kempe $\mathrm{CH}$ (eds): Child Abuse and Neglect: The Family and the Community. Cambridge: Lippincott, 1976.

8. Broadhurst D, MacDicken R: Training in the Prevention of Child Abuse and Neglect. Washington, DC: National Center on Child Abuse and Neglect, DHEW Pub. No. (OHDS) 79-30201, 1979.

9. North Carolina Juvenile Code, section 7A-523.

10. Schoenbach V: EPISAS Macrolibrary, Department of Epidemiology. Chapel Hill: UNCSPH, 1980.

11. Harrell F: Logistic Regression in the SAS Users Guide 1980. Raliegh, NC: SAS Institute, 1980.

12. Kleinbaum D, Kupper L, Morgenstern H. Quantitative epidemiology. North Scituate, MA: Duxbury Press, (in press) 1981.

13. Kleinbaum D, Kupper L, Chambliss L: Logistic regression analysis of epidemiologic data: theory and practice. Communications in Statistics 1981; (in press).

14. American Humane Association: National Analysis of Official Neglect and Abuse Reporting. Denver, the Association, 1979.

15. Gordon T, Kannel W, Halpern M: Predictability of coronary heart disease. J Chron Dis 1979; 32:427-440.

16. Maden M: The disposition of reported child abuse. Saratoga, CA: Century 21 Publishers, 1979.

17. McNeer J, Starmer F, Bartel A, et al: The nature of treatment selection in coronary artery disease. Circulation 1974; 49:606613.

\section{ACKNOWLEDGMENTS}

We gratefully acknowledge the cooperation of the North Carolina Division of Social Services, Department of Human Resources, for making their data available; Dr. Robert H. Fletcher of the Robert Wood Johnson Clinical Scholars Program for àssistance in preparation of the manuscript; and Heidi McMurray for administrative assistance. Funding support was provided by the Robert Wood Johnson Foundation and by NIH training grant number 2T32HL0F005-06. An earlier version of this paper was presented to the Southern Society for Pediatric Research on January 16, 1981 as a part of the Young Investigator Award presentations

\section{APPENDIX I}

Familial Stress Factors Included on the North Carolina Central Registry Reporting Form

Stress from being Single Parent

Marital Discord/Spouse Abuse

Insufficient Income/Unemployment

Other Financial Problems

New Baby in Home

Heavy Continuous Child Care Responsibilities

Records Show Perpetrator Abused as Child

Inadequate Housing

Lack of Social Support

Loss of Control during Discipline

Severe Discipline Acceptable to Parent

Lack of Knowledge of Child Development

Perpetrator IIIness/Handicap

Alcohol Dependence

Drug Dependence

Mental Retardation

Mental Health Problems

\section{APPENDIX II \\ Adjusted Odds Ratios: Method of Calculation}

The odds ratio is the ratio of the odds of being diseased given a particular exposure to the odds of being diseased without being exposed. In our analysis, exposure meant the presence of a specific characteristic, and diseased meant removal from the home. An odds ratio less than 1 indicates that the disease is less likely to occur in the presence of a particular exposure while a value greater than 1 reflects the increased probability of disease given a specific exposure.

The adjusted odds ratio represents the odds of disease given an exposure after controlling for the presence of all other exposures. The adjusted odds ratio can be estimated using the logistic model

$$
\begin{aligned}
& P\left(\text { removal given characteristics } X_{1}, \ldots, X_{k}\right) \\
& =\left\{1+\exp \left(b_{0}+b_{1} X_{1}+b_{2} X_{2}+\cdots+b_{k} X_{k}\right)\right\}^{-1}
\end{aligned}
$$

(continued next page) 


\section{Appendix II (continued)}

where $X_{1}, \ldots, X_{k}$ are continuous including interaction terms. If a characteristic has $t$ discrete mutually exclusive categories, it can be converted to $\mathrm{t}-1$ variables each having the value zero or one depending on the presence or absence of that characteristic. The odds ratio is meaningful only for the zero-one variables. The formula for the odds ratio holding all variables constant except the $\mathrm{i}^{\text {th }}$ variable is

$$
\mathrm{OR}_{\mathrm{i}}=\exp \left(\beta_{\mathrm{i}}+\sum_{\mathrm{j}=1}^{\mathrm{m}} \Delta_{\mathrm{j}} \mathrm{X}_{\mathrm{j}}\right)
$$

where $\beta_{i}$ is the estimated regression coefficient of the $i^{\text {th }}$ variable defined above and where $\Delta_{j}$ is the regressior coefficient of the $j^{\text {th }}$ interaction term involving variable $X_{i}$. The $X_{j} s$ may be zero-one or continuous, and $m$ is the number of such interaction terms. The confidence interval derived by Kleinbaum et al $^{13}$ is:

$$
\mathrm{OR}_{\mathrm{i}}\left\{\exp \left( \pm \mathrm{t}_{\mathrm{n}-2}, 1-\alpha / 2 \sqrt{\operatorname{Var}}\left(\operatorname{lnOR} \mathrm{R}_{\mathrm{i}}\right)\right\}\right.
$$

where $t_{n-2,1-\alpha / 2}$ is the $100(1-\alpha / 2)^{\text {th }}$ percentile of a student's $t$ distribution with $n-2$ degrees of freedom, $n$ being the overall sample size, and

$$
\operatorname{Var}\left(\ln O R_{i}\right)=\operatorname{Var}\left(\beta_{i}+\sum_{j=1}^{m} \Delta_{j} X_{j}\right) .
$$

This confidence interval is valid only for large sample sizes.

\section{2-83 Oncology Fellowship Plans Announced by ASHP}

Applications for two one-year fellowships in 1982-83 for pharmacists interested in oncology practice are now being accepted by the American Society of Hospital Pharmacists Research and Education Foundation.

The Foundation's Oncology Fellowship program is funded by Bristol Laboratories of Syracuse, NY, and offered in cooperation with the ASHP SIG on Oncology Pharmacy Practice. The program, established in 1978, was the first of the Foundation's series of clinical specialty fellowships. Bristol Laboratories has earmarked an annual contribution of more than $\$ 47,000$ to the Foundation to fund the Oncology Fellowship program. In four years, Bristol has invested more than $\$ 180,000$ to fund the program.

The deadline date to apply for the $1982-83$ program is August 14,1981 .

Each fellowship provides a stipend of $\$ 16,500$ for the fellow to spend one year at a cancer treatment center or an institution with a large progressive oncology service. Each institution selected to serve as a fellowship site will receive a $\$ 1,000$ honorarium.

An applicant for the fellowship program must be a graduate of an accredited college of pharmacy with previous hospital pharmacy experience and an expressed interest in oncology practice. Applicants also must be eligible for licensure in the state where the fellowship program will be conducted.

Purpose of the fellowship program is to enhance the proficiency of pharmacists working in oncology settings and encourage participation and cooperation within the interdisciplinary environment for the clinical management of the oncology patient. The fellows will undertake a project related to oncology practice to be completed within a one-year program.

Applicants should designate either a geographical region or a specific institution where they prefer their fellowship be conducted. Institutions selected as fellowship sites must meet the ASHP Minimum Standard for Pharmacies in Institutions and should be either a cancer treatment center or an institution with a progressive oncology service. The institution also must provide care for both the acutely ill and ambulant oncology patient.

A clinical pharmacist working in oncology pharmacy practice must be designated as the preceptor to the fellow.

A five-member panel, composed of three pharmacists, a physician and a nurse/clinician, will select the fellows and participating institutions in October 1981.

For more information or an application, contact: Ronald J. Sanchez, ASHP Research and Education Foundation, 4630 Montgomery Avenue, Washington, DC 20014; 301/657-3000. 